\title{
Existence of solutions for some two-point fractional boundary value problems under barrier strip conditions
}

\section{Zhiyu Li and Zhanbing Bai ${ }^{*}$ (D)}

"Correspondence:

zhanbingbai@163.com

${ }^{1}$ College of Mathematics and

Systems Science, Shandong

University of Science and

Technology, Qingdao, P.R. China

\begin{abstract}
In this paper, we are dedicated to researching the boundary value problems (BVPs) for equation $D^{\alpha} x(t)=f\left(t, x(t), D^{\alpha-1} x(t)\right)$, with the boundary value conditions to be either: $x(0)=A, D^{\alpha-1} x(1)=B$ or $D^{\alpha-1} x(0)=A, x(1)=B$. Let the nonlinear term $f$ satisfy some sign conditions, then by making use of the Leray-Schauder nonlinear alternative, some existence results are obtained. In the end, an example is given to verify the main results.
\end{abstract}

Keywords: Barrier strips; Conformable fractional derivative; Boundary value problems

\section{Introduction}

In the last several years, because the fractional calculus theory has been extensively used in non-Newtonian fluid mechanics, diffusion and transportation theory, engineering, biology, image processing, and other fields [9, 12, 15-19, 21, 24, 25, 35, 36, 38, 41-47], the fractional differential equations (FDEs) have been researched with different methods by many scholars. Many interesting results have been obtained $[1-8,10,11,13,14,17,23,26,30-$ 32, 35, 36, 40, 48-51].

In 1994, Kelevedjiev [27] investigated the nonlinear second order two-point BVP as follows by the use of the barrier strips argument and the topological transversality theorem [22]:

$$
\begin{aligned}
& x^{\prime \prime}(t)=f\left(t, x(t), x^{\prime}(t)\right), \quad t \in[0,1], \\
& x(0)=A, \quad x^{\prime}(1)=B,
\end{aligned}
$$

and got the existence results of solutions.

After that, the barrier strips technique was used by many researchers to study integerorder BVPs and IVPs (initial value problems). For instance, by making use of the barrier strips technique, the existence results for integer $p$-Laplacian BVP and first order IVP have been obtained by Kelevedjiev and Tersian, see [29] and [28]. Gao and Ma et al. generalized the idea to research the solvability for other integer BVPs such as second order three-point

(c) The Author(s) 2019. This article is licensed under a Creative Commons Attribution 4.0 International License, which permits use, sharing, adaptation, distribution and reproduction in any medium or format, as long as you give appropriate credit to the original author(s) and the source, provide a link to the Creative Commons licence, and indicate if changes were made. The images or other third party material in this article are included in the article's Creative Commons licence, unless indicated otherwise in a credit line to the material. If material is not included in the article's Creative Commons licence and your intended use is not permitted by statutory regulation or exceeds the permitted use, you will need to obtain permission directly from the copyright holder. To view a copy of this licence, visit http://creativecommons.org/licenses/by/4.0/. 
BVP [33], two-point BVP on time scales [34], difference equations BVP with $p$-Laplacian [20]. But as far as we know, the idea was hardly used to solve fractional BVPs at that time.

Recently, Khalil et al. [30] gave the definitions of conformable fractional derivative, which have many of the basic properties of integer derivatives. These good properties are conducive for scholars to study the BVPs with conformable fractional derivative. Motivated and inspired by the above papers. In 2017, He et al. [23] generalized the idea to research the fractional BVP as follows:

$$
D^{\alpha} x(t)=f\left(t, x(t), D^{\alpha-1} x(t)\right)
$$

with the boundary value conditions to be either

$$
x(0)=A, \quad D^{\alpha-1} x(1)=B,
$$

or

$$
D^{\alpha-1} x(0)=A, \quad x(1)=B,
$$

where $D^{\alpha}$ is the standard conformable fractional derivative, $\alpha \in(1,2]$ is a real number, and $f \in C\left([0,1] \times \mathbb{R}^{2}, \mathbb{R}\right)$.

Almost at the same time, Song et al. [39] considered the BVP for fractional equation (3) with inhomogeneous Dirichlet boundary conditions. By making use of the barrier strips technique and the fixed-point index theory, they acquired the existence results for the fractional Dirichlet BVP.

In this paper, we are dedicated to researching BVPs (3), (4) and (3), (5). Let the nonlinear term $f$ satisfy certain sign conditions at the origin. Then, by making use of the LeraySchauder nonlinear alternative [34] together with the barrier strips technique, not only can we get the existence results for BVPs (3), (4) and (3), (5), but also weaken the restrictions imposed on the nonlinear term $f$ in Theorem 11 and Theorem 12 of [23].

The paper is laid out as follows. In Section 2, we present some necessary notions and preliminaries, which play an essential role in our proofs. In Section 3, by applying the technique of barrier strips and the Leray-Schauder nonlinear alternative, our main results are given and proved. Finally, an example is given to verify the main results obtained.

\section{Preliminaries and lemmas}

We recall some notions and lemmas in this section.

Definition 2.1 ([26]) Let $u$ be $n$-order differentiable at $t>0$. The fractional derivative of order $\alpha \in(n, n+1]$ of a function $u:[0, \infty) \rightarrow \mathbb{R}$ is defined as

$$
D^{\alpha} u(t)=\lim _{\epsilon \rightarrow 0} \frac{u^{(n)}\left(t+\epsilon t^{n+1-\alpha}\right)-u^{(n)}(t)}{\epsilon},
$$

provided the limits of the right-hand side exist.

Lemma 2.1 ([26]) Let $t>0$. Function $u(t)$ is $\alpha$-order differentiable if and only if $u$ is $(n+1)$ order differentiable. Furthermore, the following relation holds:

$$
D^{\alpha} u(t)=t^{n+1-\alpha} u^{(n+1)}(t)
$$


Lemma 2.2 ([30]) Suppose that $a \geq 0$ and $f:[a, b] \rightarrow \mathbb{R}$ satisfies the following conditions:

(i) $f$ is continuous on $[a, b]$,

(ii) $f$ is $\alpha$-order differentiable on $(a, b)$.

Then there exists $e \in(a, b)$ such that the following relation holds:

$$
f(b)-f(a)=D^{\alpha} f(e) \frac{b^{\alpha}-a^{\alpha}}{\alpha} .
$$

Let

$$
\begin{gathered}
C^{\alpha}[0,1]=\left\{u \mid u(t)=J_{0+}^{\alpha} x(t)+C_{n} t^{n}+\cdots+C_{1} t+C_{0},\right. \\
\left.C_{i} \in \mathbb{R}, i=0,1, \ldots, n, x \in C[0,1]\right\}, \\
\|u\|_{\alpha}=\left\|D^{\alpha} u\right\|_{0}+\left\|D^{\alpha-1} u\right\|_{0}+\cdots+\left\|D^{\alpha-n} u\right\|_{0}+\|u\|_{0},
\end{gathered}
$$

where $\|u\|_{0}=\max _{t \in[0,1]}|u(t)|$.

Lemma $2.3([23])\left(C^{\alpha}[0,1],\|\cdot\|_{\alpha}\right)$ is a Banach space.

The next theorem is Leray-Schauder nonlinear alternative, which is crucial in our proofs.

Theorem 2.1 ([37]) Suppose that $U$ is a relatively open subset of a convex set $K$ in Banach space E. Assume that $N: \bar{U} \rightarrow K$ is a compact map and $p \in U$. Then either

(i) $N$ has a fixed point in $\bar{U}$; or

(ii) there are $\lambda \in(0,1)$ and $u \in \partial U$ such that $u=\lambda N u+(1-\lambda) p$.

Let $C_{B_{0}}^{\alpha}[0,1]$ be the subspace of $C^{\alpha}[0,1]$ such that boundary condition (4) is satisfied. Consider the BVPs:

$$
\begin{aligned}
& D^{\alpha} x(t)=\lambda f\left(t, x(t), D^{\alpha-1} x(t)\right), \quad t \in(0,1), \\
& x(0)=A, \quad D^{\alpha-1} x(1)=B,
\end{aligned}
$$

where $\lambda \in(0,1)$ is a real number. Define $L: C_{B_{0}}^{\alpha}[0,1] \rightarrow C[0,1]$ by $L x=D^{\alpha} x$. Obviously, $L$ is one-one mapping. So, the following theorem can be easily obtained by using the nonlinear alternative theorem.

Theorem 2.2 Suppose that $U$ is an open and bounded neighborhood of $0 \in C^{\alpha-1}[0,1]$ and problem (6), (7) has no solutions in $\partial U$ for $0<\lambda<1$. Then the problem

$$
\begin{aligned}
& D^{\alpha} x(t)=f\left(t, x(t), D^{\alpha-1} x(t)\right), \quad t \in(0,1), \\
& x(0)=A, \quad D^{\alpha-1} x(1)=B
\end{aligned}
$$

has at least one solution in $\bar{U}$.

Therefore, our analysis is simplified to constructing a set $U$ that is open and bounded such that BVP (6), (7) has no solutions in $\partial U$. 


\section{Existence results}

Theorem 3.1 Suppose that $f:[0,1] \times \mathbb{R}^{2} \rightarrow \mathbb{R}$ is continuous. Let $G_{1}, G_{2}$ be two constants such that $G_{2}<B<G_{1}$ and the following conditions are fulfilled:

(H1) $f\left(t, x, G_{1}\right) \geq 0$ for $(t, x) \in[0,1] \times[-G, G]$;

(H2) $f\left(t, x, G_{2}\right) \leq 0$ for $(t, x) \in[0,1] \times[-G, G]$,

where $G>|A|+\left|\frac{1}{\alpha-1}\right| \cdot \max \left\{\left|G_{2}\right|,\left|G_{1}\right|\right\}$. Then BVP (3), (4) has at least one solution.

Proof According to the Tietze-Urysohn lemma, we can find a continuous function $\triangle$ : $R^{2} \rightarrow[-1,1]$ such that

$$
\triangle\left(x, G_{1}\right)=1, \quad x \in[-G, G],
$$

and

$$
\triangle\left(x, G_{2}\right)=-1, \quad x \in[-G, G] .
$$

For $n \geq 1$, set $f_{n}(t, x, y)=f(t, x, y)+(1 / n) \triangle(x, y)$, then

$$
\begin{aligned}
& f_{n}\left(t, x, G_{1}\right)>0, \quad x \in[-G, G], \\
& f_{n}\left(t, x, G_{2}\right)<0, \quad x \in[-G, G] .
\end{aligned}
$$

Consider the BVPs

$$
\begin{aligned}
& D^{\alpha} x(t)=f_{n}\left(t, x(t), D^{\alpha-1} x(t)\right), \\
& x(0)=A, \quad D^{\alpha-1} x(1)=B .
\end{aligned}
$$

If we can prove that (14), (15) has a solution $x_{n}$ such that

$$
-G \leq x_{n} \leq G \quad \text { and } \quad G_{2} \leq D^{\alpha-1} x_{n} \leq G_{1}
$$

hold for all $n \in N$, then by combining (14), (15), (16) and Arzela-Ascoli theorem, the sequence $\left\{x_{n}\right\}$ has a subsequence which converges in $C^{\alpha}[0,1]$-topology to a solution $x_{0}$ for BVP (3), (4).

The set $U$ is defined by

$$
U=\left\{v \in C^{\alpha-1}[0,1] \mid-G<v<G, G_{2}<D^{\alpha-1} v<G_{1}\right\} .
$$

In order to prove that (14), (15) has a solution $x_{n}$ such that (16) holds, we only need to demonstrate, according to Theorem 2.1, that if $x \in C_{B_{0}}^{\alpha-1}[0,1]$ satisfies

$$
-G \leq x \leq G \quad \text { and } \quad G_{2} \leq D^{\alpha-1} x \leq G_{1} \text {, }
$$

and

$$
D^{\alpha} x(t)=\lambda f_{n}\left(t, x(t), D^{\alpha-1} x(t)\right),
$$


for some $\lambda \in(0,1)$, then $x \in U$, i.e.,

$$
-G<x<G \text { and } G_{2}<D^{\alpha-1} x<G_{1} \text {. }
$$

Let $x \in C_{B_{0}}^{\alpha-1}[0,1]$ satisfy (18), (19) for some $\lambda \in[0,1]$. By Lemma 2.1, there exists $d \in$ $(0, t)$ such that the following relation holds:

$$
x(t)-x(0)=D^{\alpha-1} x(d) \cdot \frac{t^{\alpha-1}}{\alpha-1}, \quad d \in(0, t) .
$$

Then, by the inequality $G_{2} \leq D^{\alpha-1} x \leq G_{1}$, there holds

$$
\begin{aligned}
|x(t)| & \leq\left|\frac{t^{\alpha-1}}{\alpha-1}\right| \cdot\left|D^{\alpha-1} x(d)\right|+|A| \\
& \leq\left|\frac{t^{\alpha-1}}{\alpha-1}\right| \cdot \max \left\{\left|G_{2}\right|,\left|G_{1}\right|\right\}+|A| \\
& \leq\left|\frac{1}{\alpha-1}\right| \cdot \max \left\{\left|G_{2}\right|,\left|G_{1}\right|\right\}+|A| \\
& <G .
\end{aligned}
$$

Relation (22) together with (12) and (13) implies that

$$
\begin{aligned}
& f_{n}\left(t, x(t), G_{1}\right)>0, \quad t \in[0,1] ; \\
& f_{n}\left(t, x(t), G_{2}\right)<0, \quad t \in[0,1] .
\end{aligned}
$$

Suppose that $D^{\alpha-1}\left(t_{0}\right)=G_{1}$ for some $t_{0} \in[0,1]$. We have $t_{0}<1$ since $D^{\alpha-1} x(1)=B$. Hence $D^{\alpha} x\left(t_{0}\right) \leq 0$ because $D^{\alpha-1} x(t)$ attains its maximum at $t_{0}$. However, by (23) and (19), there is

$$
\begin{aligned}
D^{\alpha} x\left(t_{0}\right) & =\lambda f_{n}\left(t_{0}, x\left(t_{0}\right), D^{\alpha-1} x\left(t_{0}\right)\right) \\
& =\lambda f_{n}\left(t_{0}, x\left(t_{0}\right), G_{1}\right) \\
& >0 .
\end{aligned}
$$

This contradiction shows that $D^{\alpha-1} x(t)<G_{1}$. Analogously $D^{\alpha-1} x(t)>G_{2}$. Thus

$$
G_{2}<D^{\alpha-1} x<G_{1}, \quad t \in[0,1]
$$

The theorem is proven.

Remark 3.1 Theorem 3.1 is a generalization of Theorem 11 in literature [22]. In [22], the conditions imposed on $f(t, x, p)$ are local to the variables $t$ and $p$ and global on $x$; however, in our Theorem 3.1, the variable $x$ is also localized.

The following theorem can be obtained in a similar way. 
Theorem 3.2 Suppose that $f:[0,1] \times \mathbb{R}^{2} \rightarrow \mathbb{R}$ is continuous. Let $G_{3}, G_{4}$ be two constants such that $G_{4}<A<G_{3}$ and the following conditions are fulfilled:

(H3) $f\left(t, x, G_{3}\right) \leq 0$ for $(t, x) \in[0,1] \times[-G, G]$;

(H4) $f\left(t, x, G_{4}\right) \geq 0$ for $(t, x) \in[0,1] \times[-G, G]$, where $G>|B|+\left|\frac{1}{\alpha-1}\right| \cdot \max \left\{\left|G_{4}\right|,\left|G_{3}\right|\right\}$. Then $B V P(3)$, (5) has at least one solution.

Remark 3.2 By comparison with the above Theorem 3.1 and Theorem 12 of [22], we can know that Theorem 3.2 is not only the "dual" of Theorem 3.1. At the same time, Theorem 3.2 is also a generalization of Theorem 12 of [22].

\section{Example}

Example 4.1 Consider the fractional BVP

$$
\begin{aligned}
& D^{\frac{3}{2}} x(t)=x(t)+D^{\frac{1}{2}} x(t)+\frac{1}{2}\left[D^{\frac{1}{2}} x(t)\right]^{2}+\left[D^{\frac{1}{2}} x(t)\right]^{3}-1, \\
& x(0)=-1, \quad D^{\frac{1}{2}} x(1)=0 .
\end{aligned}
$$

Choose $G=6, G_{1}=2, G_{2}=-2$, then

$$
\begin{array}{ll}
f\left(t, x, G_{1}\right) \geq 0, & \text { for }(t, x) \in[0,1] \times[-6,6] \\
f\left(t, x, G_{2}\right) \leq 0, & \text { for }(t, x) \in[0,1] \times[-6,6]
\end{array}
$$

By the use of Theorem 3.1, fractional BVP (27), (28) has at least one solution in $C^{\frac{3}{2}}[0,1]$.

\section{Acknowledgements}

The authors express their sincere thanks to the anonymous reviews for their valuable suggestions and corrections for improving the quality of the paper.

\section{Funding}

This work is supported by NSFC (No. 11571207), SDNSF (No. ZR2018MA011), the Taishan Scholar project, and SDUST graduate innovation project SDKDYC190237.

\section{Availability of data and materials}

Not applicable.

Competing interests

The authors declare that they have no competing interests.

\section{Authors' contributions}

All authors contributed equally to the writing of this paper. All authors read and approved the final manuscript.

\section{Publisher's Note}

Springer Nature remains neutral with regard to jurisdictional claims in published maps and institutional affiliations.

Received: 14 September 2019 Accepted: 10 December 2019 Published online: 17 December 2019

\section{References}

1. Abdeljawad, T.: On conformable fractional calculus. J. Comput. Appl. Math. 279, 57-66 (2015)

2. Bai, Z.B.: On positive solutions of a nonlocal fractional boundary value problem. Nonlinear Anal. 72(2), 916-924 (2010)

3. Bai, Z.B., Chen, Y.Q., Li, H.R., Sun, S.J.: On the existence of blow up solutions for a class of fractional differential equations. Fract. Calc. Appl. Anal. 17(4), 1175-1187 (2014)

4. Bai, Z.B., Dong, X.Y., Yin, C.: Existence results for impulsive nonlinear fractional differential equation with mixed boundary conditions. Bound. Value Probl. 2016(1), 82 (2016)

5. Bai, Z.B., Lü, H.S.: Positive solutions of boundary value problem of nonlinear fractional differential equation. J. Math. Anal. Appl. 311(2), 495-505 (2005)

6. Bai, Z.B., Zhang, S., Sun, S.J., Yin, C.: Monotone iterative method for fractional differential equations. Electron. J. Differ Equ. 2016, 6 (2016) 
7. Bai, Z.B., Zhang, Y.H.: The existence of solutions for a fractional multi-point boundary value problem. Comput. Math. Appl. 60(8), 2364-2372 (2010)

8. Bai, Z.B., Zhang, Y.H.: Solvability of fractional three-point boundary value problems with nonlinear growth. Appl. Math. Comput. 218(5), 1719-1725 (2011)

9. Chung, W.S.: Fractional Newton mechanics with conformable fractional derivative. J. Comput. Appl. Math. 290, 150-158 (2015)

10. Cui, Y.J: Uniqueness of solution for boundary value problems for fractional differential equations. Appl. Math. Lett. 51, 48-54 (2016)

11. Diethelm, K., Ford, N.J.: Analysis of fractional differential equations. J. Math. Anal. Appl. 265(2), 229-248 (2002)

12. Dong, H.H., Guo, B.Y., Yin, B.S.: Generalized fractional supertrace identity for Hamiltonian structure of NLS-MKdV hierarchy with self-consistent sources. Anal. Math. Phys. 6(2), 199-209 (2016)

13. Dong, X.Y., Bai, Z.B., Zhang, S.Q.: Positive solutions to boundary value problems of $p$-Laplacian with fractional derivative. Bound. Value Probl. 2017(1), 5 (2017)

14. Dong, X.Y., Bai, Z.B., Zhang, W.: Positive solutions for nonlinear eigenvalue problems conformable fractional differential derivatives. J. Shandong Univ. Sci. Technol. Nat. Sci. 35, 85-90 (2016) (in Chinese)

15. Fan, Y.J., Huang, X., Wang, Z., Li, Y.X.: Global dissipativity and quasi-synchronization of asynchronous updating fractional-order memristor-based neural networks via interval matrix method. J. Franklin Inst. 355(13), 5998-6025 (2018)

16. Fan, Y.J., Huang, X., Wang, Z., Li, Y.X.: Nonlinear dynamics and chaos in a simplified memristor-based fractional-order neural network with discontinuous memductance function. Nonlinear Dyn. 93(2), 611-627 (2018)

17. Fečkan, M., Marynets, K., Wang, J.: Periodic boundary value problems for higher-order fractional differential systems. Math. Methods Appl. Sci. 42(10), 3616-3632 (2019)

18. Fu, C., Lu, C.N., Yang, H.W.: Time-space fractional $(2+1)$ dimensional nonlinear Schrodinger equation for envelope gravity waves in baroclinic atmosphere and conservation laws as well as exact solutions. Adv. Differ. Equ. 2018(1), 56 (2018)

19. Fu, L., Chen, Y.D., Yang, H.W.: Time-space fractional coupled generalized Zakharov-Kuznetsov equations set for Rossby solitary waves in two-layer fluids. Mathematics 7(1), 41 (2019)

20. Gao, C.H.: Existence of solutions to p-Laplacian difference equations under barrier strips conditions. Electron. J. Differ. Equ. 2007, 59 (2007)

21. Garg, V., Singh, K.: An improved Grünwald-Letnikov fractional differential mask for image texture enhancement. Int. J. Adv. Comput. Sci. Appl. 3(3), 130-135 (2012)

22. Granas, A., Guenther, R., Lee, J.: Applications of topological transversality to differential equations. I. Some nonlinear diffusion problems. Pac. J. Math. 89(1), 53-67 (1980)

23. He, L.M., Dong, X.Y., Bai, Z.B., Chen, B.: Solvability of some two-point fractional boundary value problems under barrier strip conditions. J. Funct. Spaces 2017, Article ID 1465623 (2017)

24. He, N., Wang, J.B., Zhang, L.L., Lu, K.: An improved fractional-order differentiation model for image denoising. Signal Process. 112, 180-188 (2015)

25. Javidi, M., Nyamoradi, N.: Dynamic analysis of a fractional order prey-predator interaction with harvesting. Appl. Math. Model. 37(20-21), 8946-8956 (2013)

26. Katugampola, U.N.: A new fractional derivative with classical properties. J. Am. Math. Soc. 6(4), 1-15 (2014)

27. Kelevedjiev, P.: Existence of solutions for two-point boundary value problems. Nonlinear Anal. 22(2), 217-224 (1994)

28. Kelevedjiev, P.S., Tersian, S.: Singular and nonsingular first-order initial value problems. J. Math. Anal. Appl. 366(2), 516-524 (2010)

29. Kelevedjiev, P.S., Tersian, S.A.: The barrier strip technique for a boundary value problem with p-Laplacian. Electron. J. Differ. Equ. 2013, 28 (2013)

30. Khalil, R., Al Horani, M., Yousef, A., Sababheh, M.: A new definition of fractional derivative. J. Comput. Appl. Math. 264, $65-70(2014)$

31. Li, H.Y., Sun, J.: Positive solutions of superlinear semipositone nonlinear boundary value problems. Comput. Math Appl. 61(9), 2806-2815 (2011)

32. Li, H.Y., Zhang, J.T.: Global structure of positive solutions for some second-order multipoint boundary value problems. J. Funct. Spaces 2017, Article ID 1014250 (2017)

33. Ma, R.Y: Existence theorems for a second order three-point boundary value problem. J. Math. Anal. Appl. 212(2), 430-442 (1997)

34. Ma, R.Y., Luo, H.: Existence of solutions for a two-point boundary value problem on time scales. Appl. Math. Comput. 150(1), 139-147 (2004)

35. Mingqi, X., Radulescu, V.D., Zhang, B.: Fractional Kirchhoff problems with critical Trudinger-Moser nonlinearity. Calc Var. Partial Differ. Equ. 58(2), Article ID 57 (2019)

36. Mingqi, X., Radulescu, V.D., Zhang, B.: A critical fractional Choquard-Kirchhoff problem with magnetic field. Commun Contemp. Math. 21(4), Article ID 1850004 (2019)

37. O'Regan, D.: Boundary value problems for second and higher order differential equations. Proc. Am. Math. Soc 113(3), 761-775 (1991)

38. Rostamy, D., Mottaghi, E.: Stability analysis of a fractional-order epidemics model with multiple equilibriums. Adv. Differ. Equ. 2016(1), 170 (2016)

39. Song, Q.L., Dong, X.Y., Bai, Z.B., Chen, B.: Existence for fractional Dirichlet boundary value problem under barrier strip conditions. J. Nonlinear Sci. Appl. 10, 3592-3958 (2017)

40. Tian, Y.S., Wei, Y.F., Sun, S.J.: Multiplicity for fractional differential equations with $p$-Laplacian. Bound. Value Probl. 2018(1), $127(2018)$

41. Uchaikin, V.V.: Fractional Derivatives for Physicists and Engineers, vol. 2. Springer, Berlin (2013)

42. Wang, P.G., Li, C.R., Zhang, J, Li, T.X.: Quasilinearization method for first-order impulsive integro-differential equations. Electron. J. Differ. Equ. 2019, 46 (2019)

43. Wang, P.G., Liu, X.: Rapid convergence for telegraph systems with periodic boundary conditions. J. Funct. Spaces 2017, Article ID 1982568 (2017) 
44. Wang, X.H., Wang, Z., Huang, X., Li, Y.X.: Dynamic analysis of a fractional-order delayed SIR model with saturated incidence and treatment functions. Int. J. Bifurc. Chaos 28(14), 1850180 (2018)

45. Wang, Z., Huang, X., Zhou, J.P.: A numerical method for delayed fractional-order differential equations: based on G-L definition. Appl. Math. Inf. Sci. 7(2), 525-529 (2013)

46. Wang, Z., Wang, X.H., Li, Y.X., Huang, X.: Stability and Hopf bifurcation of fractional-order complex-valued single neuron model with time delay. Int. J. Bifurc. Chaos 27(13), 1750209 (2017)

47. Zafar, Z.U., Rehan, K., Mushtaq, M.: HIV/AIDS epidemic fractional-order model. J. Differ. Equ. Appl. 23(7), 1298-1315 (2017)

48. Zhang, S.Q.: Positive solutions for boundary value problems of nonlinear fractional differential equations. Electron. J. Differ. Equ. 2006, 36 (2006)

49. Zhang, W., Bai, Z.B., Sun, S.J.: Extremal solutions for some periodic fractional differential equations. Adv. Differ. Equ. 2016(1), $179(2016)$

50. Zhao, D.Z., Luo, M.K.: General conformable fractional derivative and its physical interpretation. Calcolo 54(3), 903-917 (2017)

51. Zou, Y.M., Cui, Y.J.: Existence results for a functional boundary value problem of fractional differential equations. Adv. Differ. Equ. 2013(1), 233 (2013)

Submit your manuscript to a SpringerOpen ${ }^{\circ}$ journal and benefit from:

- Convenient online submission

- Rigorous peer review

- Open access: articles freely available online

- High visibility within the field

- Retaining the copyright to your article

Submit your next manuscript at $\gg$ springeropen.com 